\title{
La prohibición imposible. ¿Cómo tratar a los monopolios en la Constitución?
}

Alfredo Bullard

\section{Introducción}

Uno de los aspectos centrales del modelo económico constitucional es la regulación de los monopolios. La importancia del tema ha impulsado una corriente importante que ha conducido para que cada vez más las Constituciones incluyan en su articulado normas que se refieren a la libre competencia y al rol del Estado en preservarla. Pero la experiencia histórica nos muestra que no todos los países, y en consecuencia sus Constituciones, siguen el mismo camino.

Como veremos, algunos han optado como camino, negar la existencia de monopolios. Por ello, han establecido en sus textos la prohibición abierta a la existencia de monopolios. Dentro de esa visión se usa un argumento relativamente simple: los monopolios son malos. Si son malos hay que prohibirlos. Pero estos sistemas han quedado atrapados en un imposible que ha conducido a las legislaciones y a la jurisprudencia a efectuar verdaderos «malabarismos conceptuales» para salvar una prohibición tan irreal como derogar la ley de la gravedad.

Otros países, en cambio, no han comprendido el monopolio como la antítesis de la existencia de competencia, sino, por el contrario, como un fenómeno que en ocasiones se presenta precisamente como parte del proceso competitivo. Ello no implica desentenderse del problema, sino centrar el asunto en la prohibición de prácticas mediante las cuales se distorsiona la competencia, antes que en la prohibición del monopolio en sí mismo.

Como se verá en el presente trabajo, la prohibición del monopolio es una respuesta no solamente inadecuada, sino, en la práctica, imposible de 
implementar. Tanto por la inconveniencia de la norma como por la inevitable consecuencia de que la prohibición sea continuamente incumplida, el modelo de prohibir el monopolio per se está condenado a fracasar.

Así, este trabajo demuestra la inconveniencia de establecer una norma que prohíba la existencia de monopolios, y sostiene que debe mantenerse la línea de la Constitución vigente que sanciona las prácticas y conductas desarrolladas por quienes ostentan una posición de dominio, y no la estructura del mercado en sí misma.

Sin embargo, consideramos que debe mantenerse al menos una prohibición: la de los monopolios legales. Ello porque son dichos monopolios los realmente malos para los consumidores y para la economía en general. Su prohibición implica referirse directamente a lo que sí es una conducta desarrollada por el Estado: la creación, en uso de sus facultades legislativas y administrativas, de monopolios o restricciones a la competencia que expropian el derecho de los consumidores a elegir y decidir.

\section{La prohibición imposible}

El artículo $133^{\circ}$ de la Constitución de 1979 prohibía los monopolios. Y nada perjudica más la conciencia de que la Constitución debe cumplirse, que los incumplimientos de la misma. Cuando se prohibe algo imposible de prohibir entonces la Constitución se desprestigia en su integridad.

Podemos todos coincidir que la congestión de tráfico en las calles es una situación indeseable y todos quisiéramos que no se diera. La congestión de tráfico genera pérdida de tiempo, desperdicio de recursos, accidentes de tránsito, contaminación ambiental y muchas otras situaciones similares. Pero la congestión del tráfico no es una conducta, es una situación. Esa situación es causada por numerosos factores. Cada conductor que decide sacar su automóvil a la calle contribuye, sin quererlo, a generar tráfico. Cada deseo de viaje que lleva a generar demanda de transporte

1 Entendemos por prohibición per se aquella que establece sin posibilidad de una justificación de razonabilidad, que una conducta o situación se de. Ello se contrapone con la llamada "regla de la razón» según la cual algo está prohibido solo si sus efectos no son razonables, luego del análisis de la situación concreta. Así, pasarse una luz roja está prohibido per se. Realizar una maniobra temeraria cuando uno conduce un automóvil, en cambio, está sujeto a un análisis de razonabilidad de la conducta para determinar si es o no temeraria. 
público hace lo mismo. Cada decisión de no ampliar la infraestructura vial o no reparar un semáforo o parchar un bache contribuye a más congestión. La forma de conducir los vehículos es otro factor. El tráfico no depende de nadie pero a su vez depende de todos.

¿Se imagina el lector una norma en la Constitución que prohiba la congestión de tráfico? Sería la norma más incumplida y correría una suerte similar al artículo $133^{\circ}$ de la Constitución de 1979 . Y es que cuando se prohibe la generación de una situación que se produce por la conjunción de diversos factores, ninguno de los cuales puede por sí solo ocasionar el problema pero contribuye a que ocurra, se va a ninguna parte.

Cuando la ley quiere aliviar los problemas que genera el tráfico, no prohibe la congestión. En la práctica no podría hacerlo. Solo regula algunas conductas para minimizar el riesgo de que ocurra la congestión y los daños que el tráfico genera una vez que este se presenta. Y entonces se dan las normas de tránsito, cuyo objetivo es precisamente lidiar con una situación que, todos sabemos, es en realidad inevitable, al menos si basamos el intento de evitarlo en una mera declaración de la ley o de la Constitución.

El monopolio, o más genéricamente, la concentración de poder de mercado es como la congestión de tráfico: más que una conducta, es una situación, un estado de cosas. Se puede prohibir que alguien haga algo, pero no se puede prohibir que una situación se presente como consecuencia de la interacción de numerosas personas (en este caso, proveedores y consumidores).

Es tan iluso prohibir el monopolio, como lo es tratar de establecer un número determinado de competidores. ¿Podría una Constitución decir que en una industria determinada solo puede haber tres competidores, ni más ni menos? Evidentemente no, porque el número de competidores depende de diversas condiciones, ninguna de las cuales es controlada en exclusiva por una sola persona. El número de competidores depende precisamente de la estructura del mercado, así como de las condiciones de oferta y demanda existentes. Tratar de que el funcionamiento de la economía determine una estructura distinta por decreto, es una mera ilusión.

El monopolio se puede producir por una conjunción de factores totalmente diversos. El crecimiento interno de una empresa es una modalidad. Las fusiones empresariales es otra modalidad. La quiebra o salida de competidores también puede generarlo.

Todas ellas operan en medio de una diversidad de factores distintos. El crecimiento interno no conduce al monopolio si otras empresas tam- 
bién crecen. En cambio la caída de la demanda de un producto puede conducir al monopolio, si las nuevas condiciones no permiten la existencia de más de una empresa. Una fusión no lleva al monopolio si existen condiciones que permiten el ingreso al mercado de otros competidores. La entrada de un competidor más eficiente y con mejores productos a más bajos precios puede llevar a que los que ya estaban en el mercado salgan dejando al entrante como un monopolio.

En cambio la apertura del mercado a mayor competencia puede conducir a la quiebra de varios competidores y la consolidación de unos pocos sobre los otros.

Una norma que pretenda determinar que no puede haber un solo proveedor de un bien o servicio tendría que prohibir no conductas, sino situaciones, cuya ocurrencia no depende de la voluntad de una sola persona. En otras palabras, es una prohibición cuyo obligado a cumplirla no puede ser determinado con precisión.

En esa línea una prohibición de una situación como el monopolio, la congestión del tráfico, el hambre o la pobreza es una norma ilusa, pues es una prohibición sin obligado determinado. Nadie puede ser culpado, y menos sancionado, de un resultado que es consecuencia de una serie de factores diversos, muchos de los cuales no puede controlar.

\section{3. ¿Qué tan malo es el monopolio?}

Pero adicionalmente, ello se conjuga con que no necesariamente el monopolio es económicamente ni socialmente malo, pues, en muchas ocasiones es la mejor manera de producir. Así, prohibir el monopolio muchas veces es perjudicar a los consumidores a quienes precisamente las normas que promueven la competencia deben buscar favorecer. Es perjudicar la competitividad misma al reducirse precisamente los incentivos para competir.

En un mercado determinado, un monopolio se presenta cuando se verifican ciertas condiciones específicas como la existencia de un único proveedor, la inexistencia de bienes sustitutos que de alguna manera satisfagan la demanda de los consumidores y la presencia de barreras de entrada al mercado que impidan la aparición en el corto plazo de opciones para los consumidores. 
Es claro que los monopolios pueden generar un costo social. En la medida en que el monopolista es un vendedor que puede elevar el precio de su producto en el mercado restringiendo la oferta, un grupo de consumidores, que valoriza el bien en un monto superior al de su costo de producción, no va a poder adquirirlo al precio monopólico. La competencia conduce a que el precio de los bienes refleje el costo de producirlos. El monopolio podría alejarnos de esa meta y con ello reducir la producción y elevar los precios.

Sin embargo, el monopolio puede ser muy positivo, tanto desde un punto de vista estático como desde un punto de vista dinámico.

Desde un punto de vista estático, en determinadas industrias, dada la demanda existente y los costos en que debe incurrir una empresa para producir, tener más de una empresa es malo. Ello porque la inversión necesaria para tener varias empresas compitiendo es demasiado alta para poder sustentarse en la demanda existente. Curiosamente empujar más empresas en el mercado es empujar la elevación de costos de producción en su conjunto, lo que a su vez conduce, paradójicamente, a precios más altos y/o al desperdicio de recursos escasos. En tales circunstancias, el monopolio es bueno.

Esto es especialmente cierto en economías pequeñas como la peruana. Si una economía es pequeña y pobre, es posible que la capacidad que sus consumidores tienen para demandar productos y servicios no pueda sustentar muchas empresas a la vez. El resultado natural es un mayor nivel de concentración en sus industrias.

¿Es eso malo? No necesariamente. Si se enfrenta como un hecho dado la existencia de una demanda limitada, tener muchas empresas puede ser peor. Forzar a que haya muchos competidores significa que para poder sobrevivir, todos deben fijar precios más altos. La «necesidad" de forzar la competencia podría impedir a las empresas alcanzar economías de escala y de alcance, y con ello conducir a resultados ineficientes e injustos no solo para las empresas sino para los propios consumidores quienes se verán forzados a pagar precios elevados.

En la misma línea, normas que pretendan prohibir los monopolios pueden afectar la competitividad de la industria y productores nacionales frente a la competencia extranjera. Si se "prohibe» a una empresa crecer, esta no podrá alcanzar economías de escala que la hagan eficiente. Sus costos serán mayores a los que enfrenta una empresa que, por provenir de una economía mayor a la nuestra, o simplemente, que no enfrenta legis- 
laciones de competencia que limiten tan estrictamente su capacidad de crecimiento, puede crecer más y reducir sus costos de operación. El resultado es el desplazamiento final de la empresa peruana que, limitada por la legislación que prohibe el monopolio, no puede competir con una empresa que no está sujeta a la misma limitación.

Pero también hay un aspecto dinámico que es importante tener en cuenta. A veces es bueno que el monopolio incremente sus precios precisamente para mandar señales claras al mercado sobre la escasez de los productos y servicios. El mercado competitivo funciona como un lenguaje relativamente sofisticado pero fácil de entender por todos. Los precios altos indican escasez. Los precios bajos indican abundancia. Un derrumbe que bloquea una carretera e impide traer fruta de la selva se refleja en precios inmediatamente. Esa subida de precios es buena porque indica a los consumidores que mejor cambien su dieta de fruta por unos días; los conduce a consumir otros productos más abundantes. Y la elevación de precios de la fruta crea, por otro lado, incentivos para buscar satisfacer la demanda por otros medios, como transporte aéreo o importación. Eso es bueno para los consumidores.

Cuando se produce una situación de monopolio, si la empresa sube sus precios siembra el germen de la destrucción de su monopolio pues indica que lo que produce es escaso y, por tanto, quien entra a producir o vender lo mismo ganará más. El resultado es la entrada de nuevos competidores que darán más opciones y con ello reducirán los precios. El monopolio puede ser parte de ese proceso dinámico que contribuye a asignar correctamente los recursos. Pero si los competidores no pueden entrar a competir con este monoproductor a pesar de sus precios, es porque es muy superior a ellos en términos de eficiencia. Prohibirle el monopolio sería como atar plomos a los pies a un jugador de fútbol de excepcional habilidad solo para que los demás puedan quitarle la pelota $o$ el suplente pueda entrar a reemplazarlo. Dudo mucho que la competencia futbolística se vería beneficiada con tal medida.

Bork se pronuncia de manera muy clara en ese sentido:

«Si la empresa líder en un mercado concentrado está restringiendo su producción para obtener precios por encima del nivel competitivo, sus eficiencias deben ser lo suficientemente superiores a las de sus rivales actuales o potenciales para neutralizar su comportamiento. $\mathrm{Si}$ ello no es así, los rivales estarán en la capacidad de ampliar su parti- 
cipación de mercado como consecuencia de los precios anormalmente altos y entonces la industria se desconcertará. En consecuencia, la rivalidad en el mercado automáticamente contrapesa las respectivas influencias de la eficiencia y la restricción de producción y nos lleva al tamaño de empresas y la estructura de la industria que sirve mejor a los consumidores.» ${ }^{2}$

Lo que sí nos debe preocupar es el supuesto en que producido el monopolio las barreras estatales o privadas de acceso perpetúen el monopolio e impidaen que el mercado genere una estructura competitiva. Por eso es tan importante, por un lado, prohibir el monopolio legal, es decir, el monopolio creado por el Estado, y, en segundo lugar, prohibir ciertas prácticas empresariales que contribuyen a distorsionar la competencia y la entrada o permanencia de competidores en el mercado a través de mecanismos indebidos.

\section{El rol de las normas de competencia: tutelar la expresión de las preferencias de los consumidores}

Las normas de competencia económica deben entenderse de la misma manera como son comprendidas aquellas de competencia política, es decir, como se entiende el sistema electoral. Su función es garantizar que el resultado de la agregación de preferencias de los ciudadanos sea respetada en decisiones que reflejen dichas opciones. Es decir que, al igual como uno vota por su candidato y tiene derecho a que dicho voto cuente y sea considerado, las normas de competencia deben proteger el derecho de los consumidores de «votar" por los productos y servicios que deseen y elegirlos libres de limitaciones indebidas.

2 Robert Bork, The Antitrust Paradox, Maxwell Macmillan, New York, 1993. p. 178. Traducción libre del siguiente texto: "If the leading firms in a concentrated industry are restricting their output in order to obtain prices above the competitive level, their efficiencies must be sufficiently superior to that of all actual and potential rivals to offset the behavior. Were this not so, rivals would be enabled to expand their market shares because of the abnormally high prices and would thus deconcentrate the industry. Market rivalry thus automatically weighs the respective influences of efficiency and output restriction and arrive at the firm sizes and industry structure that serve consumers best, 
Las bondades de un sistema electoral en el campo político no se miden por la calidad del Presidente o Congresista elegido, sino porque el elegido fue el preferido por los electores. La transparencia entre lo querido y lo logrado es lo que determina que el organismo electoral cumplió con su cometido.

Lo mismo ocurre con el rol del Estado al promover la competencia. Este se cumple no garantizando un resultado (muchos competidores), sino asegurando que lo que se produce es consecuencia de la decisión y deseo de los consumidores en el contexto de ciertas limitaciones económicas existentes. Si los consumidores entregan sus preferencias a pocos competidores, ese resultado debe ser respetado. Y ese rol se asegura permitiendo que no existan barreras de acceso al mercado, sean estas públicas, es decir, creadas por el propio Estado, o privadas, generadas por medio de prácticas ilegales de las empresas. Es en este último aspecto que le corresponde al Estado velar por la existencia de una sana competencia.

\section{La paradoja de la libre competencia. De cómo «soñar en el monopolio incentiva la competencia"}

Como ya se dijo, si bien el monopolio puede tener consecuencias negativas para los consumidores, su prohibición puede generar daños a esos mismos consumidores. El proceso competitivo se alimenta de la aspiración de todo empresario por aumentar su participación en el mercado. El esfuerzo de todo empresario por reducir costos y bajar precios, mejorar la calidad de sus productos o el servicio a los consumidores se orienta precisamente a aumentar la participación que dicha empresa tiene en el mercado.

Si se le pregunta a un empresario qué soñó la mañana que se levantó con una sonrisa en los labios, es que soñó que tenía un monopolio. Es ese sueño el que impulsa la actividad económica y el esfuerzo de las empresas por mejorar, por la vía de mejorar a su vez lo que ofrece a sus consumidores. Finalmente, es el deseo de ser más grande el que inspira a las empresas a ponerse al servicio de los consumidores.

Si se prohibe a rajatabla el monopolio y se imponen sanciones por crecer, sin analizar las causas del crecimiento empresarial, ese sueño se volverá una pesadilla y el resultado será reducir los incentivos para mejorar la situación de los consumidores. Ese sueño, de no existir barreras al mercado, casi nunca se realizará. La propia competencia (es decir, el deseo de 
todos los competidores por alguna vez alcanzar un monopolio) controla esa capacidad. Esa es la paradoja: que exista competencia implica aceptar el riesgo de un monopolio.

Lo que entonces nos debe preocupar, antes que el monopolio en sí, son los medios por los cuales se alcanza una mayor participación de mercado, de un lado, y los posibles abusos que, una vez alcanzada una posición dominante en el mercado, puedan cometerse. Por ello, tal como nos recuerda Ross en la siguiente cita, no preocupa tanto el monopolio, sino el carácter indebido del medio por el que se alcanza o defiende:

«[...] el elemento final del intento de monopolización requiere demostrar que el demandado se involucró en una conducta indebida. Dado que la mera tenencia de un monopolio no es ilegal bajo la Sección 2 (de la Sherman Act), el mero intento de alcanzar tal poder no puede ser prohibido. Por el contrario, el demandado debe haberse involucrado en una conducta que, de ser exitosa, pueda ser caracterizada como una adquisición "intencional» de poder monopólico. El demandado que inventa un nuevo producto puede estar intentando asegurar su monopolio mediante innovación, pero dicha conducta obviamente no puede constituir un intento ilegal de monopolización.» ${ }^{3}$

Esta paradoja es precisamente la base de la evolución que, como veremos, se ha producido en el enfoque que el Derecho da al problema de los monopolios. La competencia no es solo un problema de precios. Tiene que ver con inversión, innovación, calidad y servicios a los competidores. A veces fomentar una mayor competencia de precios reduce los incentivos para innovar o invertir. Es decir, según esa paradoja, precisamente generar más competencia por precios puede reducir la competencia en otros elementos también importantes para los consumidores.

3 Ross, op cit, p. 101. Traducción libre del siguiente texto: «the final element of attempted monopolization requires a showing that the defendant engaged in misconduct. Because the mere attainment of monopoly power is not illegal under Section 2, the mere attempt to attain such power likewise cannot be probibited. Rather, the defendant must have engaged in conduct that, if successful, could be characterized as the "willful» acquisition of monopoly power. A defendant who invents a superior product may attempt to secure a monopoly through its innovation, but such conduct obviously would not constitute illegal attempted monopolization». 
Esto explica, por ejemplo, el reconocimiento universal que el Derecho da a las patentes de invención. Esas patentes pueden conceder un monopolio temporal al creador de una invención para explotarla. Ello, sin duda, genera precios más altos para los productos derivados de dicha creación en el tiempo que dura la vigencia de la patente. Pero reconocemos dicho monopolio, porque si no lo respetamos reducimos los incentivos futuros para crear nuevas invenciones. La renta monopólica temporal se acepta ante el riesgo que nunca se desarrolle una invención por falta de incentivos para usar la creatividad humana.

Lo mismo ocurre con otros aspectos de la actividad económica. Si una empresa invierte para mejorar su producción y así hacer productos mejores, más baratos y más seguros para los consumidores con el objeto de desplazar a su competencia, y luego se le priva del derecho de crecer, entonces deja de invertir. Yal dejar de invertir perjudica a los consumidores que ya no gozarán de los beneficios de dicha inversión (mejores productos, mejor tecnología, mejores condiciones, etc.).

Como bien dice el tratadista peruano Baldo Kresalja:

«[...] no deben confundirse las limitaciones a la competencia que nacen de la competencia misma de las que tienen su origen en una práctica destinada expresamente a ese fin, pues mientras las primeras son la esencia misma del sistema competitivo; las segundas son una perversión del sistema y constituyen el objeto del Derecho antitrust $[\ldots]{ }^{4}$

Irwing Kaufman, el famoso juez norteamericano que resolvió el caso United States v. Alcoa decía:

"[...] el comperidor exitoso, al que se le ha exigido competir, no debe ser castigado si es que gana” ${ }^{6}$

4 Baldo Kresalja, “La reserva de actividades económicas a favor del Estado y el régimen de los monopolios en las Constituciones de 1979 y 1993", en : Ius et Veritas No 22, p. 299.

5148 F. 2 d 416 (2d Cir. 1945).

6 Traducción libre del siguiente texto: «[...] the successful competitor, having been urged to compete, must not be turned upon he wins». 
En la misma línea, Viscusi, Vernon y Harrington señalan que debe diferenciarse la adquisición intencional, mediante estrategias indebidas, de poder de mercado, del caso en que el poder de mercado se logra por crecimiento o desarrollos propios derivados del esfuerzo empresarial, superioridad de sus productos o un simple accidente histórico. ${ }^{7}$

Comentando la legislación norteamericana, estos mismos autores señalan:

«[...] dada la existencia de poder monopólico, la segunda parte del análisis de la regla de la razón es determinar cuándo el monopolio fue adquirido y/o mantenido por prácticas que no pueden calificarse como eficiencia superior o accidente histórico. Esto es, un monopolio sobre bienes causado en una mayor eficiencia en producir esos bienes no es una violación a la Sherman Act.» ${ }^{8}$

Es que no hay que perder de vista el impacto invisible de prohibir el monopolio. Normalmente solo nos fijamos en la consecuencia ocurrida cuando el monopolio se da y el titular de dicho monopolio abusa del mismo, eleva los precios y limita las opciones de los consumidores, pero perdemos de vista cuánto perdería la sociedad si se redujeran los incentivos para competir mediante la penalización del crecimiento empresarial.

Esta paradoja no tiene una solución fácil. Sin embargo a la fecha, el mejor modelo desarrollado legislativamente es el reconocido por la Constitución actual, es decir, no penalizar el monopolio sino la práctica monopólica o restrictiva de la competencia.

Un concepto central para entender ello es el de «daño concurrencial». La posibilidad que la competencia beneficie a los consumidores lleva implícita la posibilidad que la competencia dañe a los competidores. Y la opción por la libre competencia es una opción a favor de los consumidores. La manifestación más clara de ese daño al competidor es la pérdida de participación de una empresa o incluso su eventual salida del mercado.

7 Kip Viscusi, John Vernon y Joseph Harrington, Economics of Regulation and Antitrust, MIT Press, London, 1997, p. 266.

8 Ibid, p. 270. Traducción libre del siguiente texto: "given the existence of monopoly power, the second part of the rule of reason test is to determine whether the monopoly was acquired and/or maintained by practices that cannot qualify as superior efficiency or historical accident. That is, a monopoly over widgets because of superior efficiency in producing widgets is not in vislation of Sherman Actw. 
Pero ese es un daño legítimo. A ese daño se le conoce como daño concurrencial.

Se considera como daño concurrencial a todo perjuicio causado a los competidores mediante el uso legítimo de políticas de precios, calidad y condiciones ofrecidas a los consumidores. En términos sencillos es daño concurrencial el que se basa en la elección que los propios consumidores hacen libremente, y que implica desplazar sus preferencias de una opción a otra.

Solo cuando ese desplazamiento es producido por actos diferentes a méritos legítimos, el Derecho debe preocuparse por ello.

Si la concentración del mercado responde a preferencias de los consumidores entonces es legítima. Ello no quiere decir que solo el crecimiento interno justifica la concentración de mercado. Esta puede provenir de otros canales, como sería el caso de una fusión. En ese supuesto, si bien la concentración inicial puede ser consecuencia de un acto empresarial, si esta genera eficiencias que repercuten en el bienestar de los consumidores y no existen barreras de entrada al mercado, la preferencia de los consumidores por los productos y servicios de la nueva empresa concentrada es una señal de aprobación que el sistema legal debe respetar. Así, la no entrada de otros competidores nuevos debe leerse como el voto de los consumidores a favor de gozar de los beneficios generados por la concentración, salvo que existan prácticas privadas ilegítimas dirigidas a frenar dicha entrada en contra de la ley. Y a ello debe añadirse que no existen incentivos claros para que las empresas se fusionen si no va generar eficiencias que reducen costos y mejoran el funcionamiento del proceso productivo. Si la fusión es ineficiente elevará los costos de producir y con ello perjudicará no solo a los consumidores sino a la propia empresa.

Bork se pronuncia en ese sentido, respecto de las eficiencias del crecimiento interno y de las fusiones entre empresas:

«[...] tanto el crecimiento interno como las fusiones horizontales eliminan rivalidad, y lo hacen de una manera más permanente que un acuerdo de cartel. [...] La razón por la que no declaramos estas eliminaciones de rivalidad per se ilegales es que involucran integración de la actividad productiva y en consecuencia tienen la capacidad de crear eficiencia. Las integraciones contractuales [...] también son capaces de crear eficiencias. El derecho de la integración contractual y de la 
integración de propiedad deben, por tanto ser simétricas. No hay razón para suspender la regla per se en un área y no en la otra.."

En un sentido bastante similar Ross y comentando el trabajo de Ronald Coase, Premio Nobel de Economía y de Oliver Williamson, nos dice:

"Las implicaciones de la "teoría de la empresa» es que el derecho de la Competencia no debería ser escéptico de que las fusiones, los joint ventures o los contratos entre empresas, y deberían evitar interferir en estas maneras de hacer negocios de manera eficiente. $\eta^{10}$

Así, no debe penalizarse la capacidad de lograr la preferencia de los consumidores, sino las prácticas que distorsionen dichas preferencias o consigan resultados antagónicos con ellas. Ese es el rol del Derecho en este campo. ${ }^{11}$

Esa línea explica, como bien dice el tratadista peruano Baldo Kresalja, la perspectiva adoptada por la doctrina moderna del Derecho de la competencia, la que ha desarrollado con un alto nivel de sofisticación el concepto de abuso de posición de dominio en el mercado:

"El gran desarrollo que en la doctrina y la legislación modernas tiene el concepto de «abuso de posición de dominio» se basa, entre otras

9 Bork, op. cit., p 264. Traducción libre del siguiente texto: «both internal growth and horizontal merger eliminate rivalry and they do so more permanently than do cartel agreements. Price are fuxed and markets allocated within firms. The reason we do not make these eliminations of rivalry illegal per se is that they involve integration of productive activities and therefore have the capacity to create efficiency. Contract integrations (including those integrations involving price-fixing and market-division agreements) are also capable of producing efficiency. The law of contract integration and of ownership integration should, therefore, be made symmetrical. There is no justification for suspending the per se rule in one area and not the othen

10 Stephen Ross, Principles of Antitrust Law, The Foundation Press, New York, 1993, p. 4. Traducción libre del siguiente texto: "Thus, the implications of the "theory of the firm" is that antitrust law should not be skeptical of mergers, joint ventures, or contract agreements among firms, and should be wary interfering with these ways of efficiently doing business."

11 Esto explica porqué no es recomendable el control de fusiones en una economía pequeña. El mercado suele tener mecanismos más efectivos para discriminar las fusiones dañinas de aquellas que no lo son. En cambio la regulación de fusiones eleva los costos de transacción del reordenamiento empresarial, reduce los incentivos a la inversión y conduce a que las empresas soporten costos que, finalmente son pagados por los consumidores. 
razones, en la creencia que ya no es pertinente condenar a los monopolios u oligopolios por sí mismos, sino las prácticas abusivas al amparo de una posición de dominio.. ${ }^{12}$

Esta perspectiva explica posiciones como la del español José Eugenio Soriano, quien indica:

«[...] la libre competencia es una técnica de lucha contra el abuso de los monopolios. Al menos contra los monopolios no conseguidos en justa competencia, a los cuales hay que vigilar estrechamente precisamente para que no abusen frente al ciudadano y frente a potenciales competidores." ${ }^{13}$

Y es que no puede cuestionarse el monopolio en sí mismo, pues como estableció en el sistema comunitario europeo, al resolver el célebre caso Michelin:

«Declarar que una empresa tiene una posición dominante no es por sí mismo un reproche sino simplemente significa que, sin tener en cuenta las razones por las que tiene posición dominante, la empresa de que se trata tiene una responsabilidad especial de no permitir que su conducta impida una competencia genuina y no falseada en el mercado común.» ${ }^{14}$

\section{El modelo constitucional de 1979 vs. el modelo constitucional de 1993: Prohibición de monopolio vs. prohibición de prácticas}

A la luz de los conceptos señalados en los puntos anteriores uno puede entender la notoria diferencia existente entre la Constitución de 1979 y la Constitución de 1993. Casi podríamos decir que la evolución del Derecho de la Competencia en sus más de cien años de existencia está resumi-

12 Baldo Kresalja, «La reserva de actividades económicas a favor del Estado y el régimen de los monopolios en las constituciones de 1979 y 1993 ", en: Ius Et Veritas No 22, p. 295.

13 José Soriano García, Derecho Público de la Competencia, Madrid, 1998, p. 51.

14 Asunto 322/81 Michelin c. Comisión (1983). Rep. 3461. 
da en la variación de catorce años entre el texto de 1979 y el texto de 1993.

La legislación de libre competencia fue denominada en sus orígenes (y aún conserva la "chapa") de "legislación antimonopolios". Es importante notar dos elementos de esta terminología. La primera es que denota una posición antagónica contra la existencia de los monopolios en sí mismos. Así, según esa terminología la legislación combate el monopolio.

El segundo aspecto relevante es que el término "antimonopolio" es una mala traducción del inglés. Como sabrá el lector, a esta legislación se le conoce en el sistema anglosajón como el Derecho uantitrust». Pero antitrust no quiere decir antimonopolios. La palabra «trust» alude acuerdos entre empresas y denota que con la promulgación de la Sherman Act en los Estados Unidos, a finales del siglo XIX lo que estaba en la mente de quienes bautizaron esta rama del Derecho eran principalmente los carteles de precios. Si bien la norma también hacía referencia a prácticas de monopolización y abuso de poder de mercado, quienes bautizaron a la nueva rama pensaron antes en los acuerdos anticompetitivos, principalmente aquellos en los que un grupo de competidores se ponen de acuerdo para fijar precios o distribuirse mercados y así restringir la competencia entre ellos.

La palabra "antimonopolios" con la cual llega a nuestra legislación, además de una mala traducción, denota que el problema es combatir el monopolio en sí mismo, y no la práctica que restringe o afecta la competencia. Esto contribuyó por años a pensar que el problema era el monopolio en sí mismo y no las prácticas que distorsionan la competencia.

La evolución poco a poco fue mostrando los inconvenientes de considerar al monopolio como el enemigo, para que la legislación, y sobre todo los encargados de aplicarla, fueran comprendiendo que su rol, antes que destruir monopolios, era promover competencia. Así, esta rama fue, poco a poco, siendo rebautizada, para llamarse "políticas de ccompetencia", «llegislación de llibre ccompetencia», «legislación de ppromoción de la ccompetencia» $u$ otros nombres similares.

Hoy casi ninguna legislación -al menos de las modernas- se autodenomina a sí misma como "legislación antimonopolios»; por lo general, usan un nombre más orientado a la promoción del proceso competitivo. Ello implica no solo un cambio de nombre, sino de perspectiva. La labor de la legislación, antes que destructiva, es constructiva. Antes que perseguir un resultado (que no haya monopolios), persigue que se den las condiciones para que la competencia funcione. 
Como se dijo, este proceso evolutivo de un siglo, que tiene por justificación los fundamentos desarrollados en los puntos anteriores de este trabajo, se vio reflejado en catorce años de historia de nuestro texto constitucional.

Así, recordemos nuevamente el texto del artículo $133^{\circ}$ de la Constitución de 1979:

"Artículo $133^{\circ}$.- Están prohibidos los monopolios, oligopolios, acaparamientos, prácticas y acuerdos restrictivos en la actividad industrial y mercantil. La ley asegura la normal actividad del mercado y establece las sanciones correspondientes».

Esta norma siguió la tradición de todas las constituciones peruanas del siglo XX, que con textos bastante similares, prohibieron el monopolio. Si bien la norma también hace mención a prácticas y acuerdos restrictivos, prohíbe a rajatabla el monopolio. Pero además el texto constitucional de 1979 no menciona ni una vez el término "competencia» o "libre competencia» salvo para referirse al sentido de "competencia», como facultad o capacidad de decisión de una autoridad pública.

Esta omisión tiene además un sesgo ideológico claro. Note el lector que en el propio artículo $133^{\circ}$ se escabulle el uso del término «libre competencia» para tener una redacción forzada y poco precisa al referirse a "prácticas y acuerdos restrictivos de la actividad mercantil».

Allí la Constitución de 1979 perdió perspectiva. Lo que beneficia a los consumidores y a la economía en general no es que no haya monopolios, sino que haya competencia. Pero la palabra "competencia" brilla por su ausencia en el texto constitucional.

De hecho la Constitución de 1979 era «antimonopólica».

La situación cambia radicalmente con el texto constitucional de 1993, casi como si hubieran pasado cien años entre un texto y el otro. El artículo $61^{\circ}$ de la Constitución establece:

«Artículo 61․- El Estado facilita y vigila la libre competencia. Combate toda práctica que la limite y el abuso de posiciones dominantes o monopolios. Ninguna ley ni concertación puede autorizar ni establecer monopolios." 
Varios puntos son destacables. El primero es que no hay prohibición del monopolio, sino la asignación de una obligación del Estado de facilitar y vigilar la libre competencia (ya usa ese término evadido en el texto de 1979). Así, su labor principal es promover la competencia antes que perseguir monopolios.

En segundo lugar, el modelo constitucional de 1993 seńala que lo que se combate es la práctica que limitae la competencia (es decir, que pueda crear un monopolio o un efecto análogo al mismo, como un cartel entre competidores por ejemplo) o el abuso de posiciones monopólicas o dominantes en el mercado. Ae descarta la eliminación del monopolio y se centra el tema en las conductas que fomentan la concentración de mercado por medios ilegítimos o el abuso del poder que confiere un monopolio.

En tercer lugar, prohíbe el monopolio legal como única forma de monopolio vedada por la Constitución ${ }^{15}$. Si bien esta última parte recoge un texto algo confuso, por las referencias a concertaciones que crean monopolios, cuando las concertaciones no tienen que hacer con acumular poder de mercado en un monopolio, sino limitar la competencia para que varios, mediante un acuerdo, se beneficien de cargar precios más altos.

Sin perjuicio que el texto es perfectible, la superioridad en técnica legal y en comprensión del fenómeno económico respecto del texto de 1979. es notoria. Y retroceder a un texto similar al anterior sería no solo inadecuado, sino ilusorio porque no podría ser puesto en vigencia.

Así, como bien señala Kresalja:

«En las normas constitucionales peruanas del siglo $\mathrm{XX}$, el régimen de los monopolios ha evolucionado, pasando de una prohibición contra los monopolios privados a su aceptación tácita. Se reconoce así que la concentración de poder económico en manos privadas no es siempre algo negativo o sancionable, siendo lo propio vigilar que ello no termine perjudicando a los consumidores, más aún cuando el éxito empresarial, en algunos casos, puede responder al reconoci-

15 En realidad existe otro supuesto prohibido, en el segundo párrafo del artículo $61^{\circ}$, referido al monopolio de los medios de comunicación, pero ello, más que por razones de competencia pura, se centra en una regla que garantice el ejercicio plural de la libertad de expresión. 
miento que los propios consumidores otorgan a las empresas que mejor atienden sus necesidades. $\rangle^{16}$

\section{Los modelos constitucionales y las legislaciones de libre compe- tencia comparados}

El análisis de los textos constitucionales que regulan el tema de las políticas de competencia, nos conduce a la conclusión que existen modelos que establecen una prohibición del monopolio, mientras otros solo se refieren a la prohibición de las prácticas monopólicas.

Sin embargo, en los países que han prohibido expresamente en sus constituciones el monopolio, las leyes y la jurisprudencia que han desarrollado dichos preceptos constitucionales han restringido el alcance de la prohibición, quizás simplemente como un reconocimiento al hecho de que se trata prohibir lo que es imposible prohibir.

Conviene hacer una breve referencia a los dos modelos de legislación de competencia más importantes del mundo: el sistema norteamericano, que regula estos temas en la llamada Sherman Act, dictada a finales del siglo XIX, y el sistema europeo que regula este tema en los artículos $85^{\circ}$ y $86^{\circ}$ del Tratado de Roma. Ninguno de estos sistemas ha prohibido a rajatabla el monopolio, sino las prácticas abusivas. Los órganos que han aplicado estas regulaciones se han mantenido precisamente en esa línea.

En el caso de la Sherman Act, la Sección 1 se refiere a los acuerdos de precios o restrictivos de la competencia. La Sección 2 se refiere a los casos de monopolización. Dicha norma no cuestiona la existencia del monopolio, sino solo las prácticas indebidas que tienen por objeto monopolizar un mercado. ${ }^{17}$

Por su parte, el Tratado de Roma — virtualmente la Constitución de la Unión Europea- tampoco prohíbe el monopolio, sino la práctica monopólica. Con una estructura similar a la Sherman Act, regula en su

16 Baldo Kresalja, «La reserva de actividades económicas a favor del Estado y el régimen de los monopolios en las constituciones de 1979 y 1993", en: Ius Et Veritas No 22, p. 301 .

17 «Section 2. Every person who shall monopolize or attempt to monopolize, or combine or conspire with any other person or persons, to monopolize any part of the trade or commerce among several States, or with foreign nations, shall be deemed guilty of a felony [...]". 
artículo $85^{\circ}$ los acuerdos entre competidores, y en el $86^{\circ}$ el tema del abuso de posición de dominio en el mercado. Este último artículo, más pertinente al tema del monopolio, tampoco lo prohíbe, y solo sanciona el aprovechamiento indebido de una posición de dominio. ${ }^{18}$

Entre las Constituciones que prohíben expresamente el monopolio se encuentran la de Bolivia $^{19}$-, aunque con un lenguaje ambiguo que permite interpretar que no es una prohibición absoluta-Costa Rica, ${ }^{20} \mathrm{Gua}-$ temala, ${ }^{21}$ México, ${ }^{22}$ Panamá, ${ }^{23}$ Paraguay, ${ }^{24}$ República Dominicana, ${ }^{25}$ Venezuela, ${ }^{26}$ entre otros.

18 Artículo $86^{\circ}$.-Será incompatible con el mercado común y quedará prohibida, en la medida en que pueda afectar al comercio entre los Estados miembros, la explotación abusiva, por parte de una o más empresas, de una posición dominante en el mercado común o en una parte sustancial del mismo.

[...]"

19 Artículo $134^{\circ}$ - No se permitirá la acumulación privada de poder económico en grado tal que ponga en peligro la independencia económica del Estado. No se reconoce ninguna forma de monopolio privado. Las concesiones de servicios públicos, cuando excepcionalmente se hagan, no podrán ser otorgadas por un período mayor de cuarenta años.

20 Artículo $46^{\circ}$.- Son prohibidos los monopolios de carácter particular. y cualquier acto, aunque fuere originado en una ley, que amenace o restrinja la libertad de comercio, agricultura e industria.

Es de interés público la acción del Estado encaminada a impedir toda práctica o tendencia monopolizadora.

Las empresas constituidas en monopolios de hecho deben ser sometidas a una legislación especial.

Para establecer nuevos monopolios en favor del Estado o de las Municipalidades se requerirá la aprobación de dos tercios de la totalidad de los miembros de la Asamblea Legislativa.

21 Artículo $130^{\circ}$ - Prohibición de monopolios. Se prohiben los monopolios y privilegios. El Estado limitará el funcionamiento de las empresas que absorban o tiendan a absorber, en perjuicio de la economía nacional, la producción en uno o más ramos industriales o de una misma actividad comercial o agropecuaria. Las leyes determinarán lo relativo a esta materia. El Estado protegerá la economía de mercado e impedirá las asociaciones que tiendan a restringir la libertad del mercado o a perjudicar a los consumidores.

22 Artículo $28^{\circ}$.- En los Estados Unidos Mexicanos quedan prohibidos los monopolios, las prácticas monopólicas, los estancos y las exenciones de impuestos en los términos y condiciones que fijan las leyes. El mismo tratamiento se dará a las prohibiciones a titulo de protección a la industria.

23 Artículo $293^{\circ}$.- No habrá monopolios particulares.

24 Artículo $107^{\circ}$.- De la Libertad de Concurrencia. Se garantiza la competencia en el mercado. No serán permitidas la creación de monopolios y el alza o la baja artificiales de 
Sin embargo la declaración Constitucional no opera en la práctica. Basta revisar las legislaciones de competencia de los países que tienen estas normas constitucionales para descubrir que las mismas no contienen propiamente prohibiciones a los monopolios. En la mayoría de casos como en Panamá, Venezuela o México, las legislaciones solo prohíben las conductas abusivas y eventualmente incluyen algún sistema de control de fusiones. Pero nada más. Así, la propia realidad ha forzado a dar una interpretación restrictiva a las normas constitucionales.

Lo que suele ocurrir es que estas legislaciones han interpretado la prohibición a los monopolios como proscripción de la posibilidad de que el Estado conceda monopolios a particulares. En otras palabras, se ha interpretado que la proscripción no se aplica de manera general a todo monopolio, sino básicamente al monopolio legal. A través de esta línea

precios que traben la libre concurrencia. La usura y el comercio no autorizado de artículos nocivos serán sancionados por la Ley Penal.

25 Artículo $8^{\circ}$.- Se reconoce como finalidad principal del Estado la protección efectiva de los derechos de la persona humana y el mantenimiento de los medios que le permitan perfeccionarse progresivamente dentro de un orden de libertad individual y de justicia social, compatible con el orden público, el bienestar general y los derechos de todos. Para garantizar la realización de esos fines se fijan las siguientes normas_[...]:

12. La libertad de empresa, comercio e industria. Solo podrán establecerse monopolios en provecho del Estado o de instituciones estatales. La creación y organización de esos monopolios se harán por ley.

26 Artículo $113^{\circ}$.- No se permitirán monopolios. Se declaran contrarios a los principios fundamentales de esta Constitución cualquier acto, actividad, conducta o acuerdo de los y las particulares que tengan por objeto el establecimiento de un monopolio o que conduzcan, por sus efectos reales e independientemente de la voluntad de aquellos o aquellas, a su existencia, cualquiera que fuere la forma que adoptare en la realidad.

También es contraria a dichos principios el abuso de la posición de dominio que un particular, un conjunto de ellos o ellas o una empresa o conjunto de empresas, adquiera o haya adquirido en un determinado mercado de bienes o de servicios, con independencia de la causa determinante de tal posición de dominio, así como cuando se trate de una demanda concentrada. En todos los casos antes indicados, el Estado adoptará las medidas que fueren necesarias para evitar los efectos nocivos y restrictivos del monopolio, del abuso de la posición de dominio y de las demandas concentradas, teniendo como finalidad la protección del público consumidor, los productores y productoras y el aseguramiento de condiciones efectivas de competencia en la economía.

Cuando se trate de explotación de recursos naturales propiedad de la nación o de la prestación de servicios de naturaleza pública con exclusividad o sin ella, el Estado podrá otorgar concesiones por tiempo determinado, asegurando siempre la existencia de contraprestaciones o contrapartidas adecuadas al interés público. 
interpretativa dichos ordenamientos jurídicos han terminado , en la misma situación en la que se encuentran los regímenes jurídicos cuyas Constituciones no prohíben expresamente el monopolio, sino algunas de las prácticas desarrolladas por estos.

Esto demuestra la superioridad técnica, conceptual y práctica de no prohibir expresamente el monopolio, sino solo algunas de las conductas desarrolladas por estos o que los generan.

Por su parte, abundan también los textos constitucionales, normalmente más modernos, que no prohíben el monopolio sino algunas de las prácticas desarrolladas por estos. Entre estas se encuentran las Constituciones de Argentina, ${ }^{27} \mathrm{Brasil},{ }^{28}$ Colombia, ${ }^{29}$ Ecuador,${ }^{30}$ entre otros.

27 Artículo $42^{\circ}$.- Los consumidores y usuarios de bienes y servicios tienen derecho, en la relación de consumo, a la protección de su salud, seguridad e intereses económicos; a una información adecuada y veraz; a la libertad de elección y a condiciones de trato equitativo y digno.

Las autoridades proveerán a la protección de esos derechos, a la educación para el consumo, a la defensa de la competencia contra toda forma de distorsión de los mercados. al control de los monopolios naturales y legales, al de la calidad y eficiencia de los servicios públicos, y a la constitución de asociaciones de consumidores y de usuarios.

La legislación establecerá procedimientos eficaces para la prevención y solución de conflictos, y los marcos regulatorios de los servicios públicos de competencia nacional, previendo la necesaria participación de las asociaciones de consumidores y usuarios y de las provincias interesadas, en los organismos de control.

28 Artículo $173^{\circ}$.- Exceptuados los casos previstos en esta Constitución, la explotación directa de actividades económicas por el Estado solo será permitida cuando sea necesaria por imperativos de seguridad nacional o de interés colectivo relevante, conforme a la definición de la ley.

1). La empresa pública, la sociedad de economía mixta y otras entidades que exploten actividades económicas están sujetas al régimen jurídico propio de las empresas privadas, incluso en lo relativo a las obligaciones laborales y tributarias.

2). Las empresas públicas y las sociedades de economía mixta no podrán gozar de privilegios fiscales no aplicables a las del sector privado.

3). La ley regulará las relaciones de la empresa pública con el Estado y la sociedad.

4). La ley reprimirá el abuso de poder económico que tienda a la dominación de los mercados, a la eliminación de la concurrencia y el aumento arbitrario de los beneficios.

5). La ley, sin perjuicio de la responsabilidad individual de los directivos de la persona jurídica, establecerá la responsabilidad de ésta, sujetándola a las sanciones compatibles con su naturaleza, en los actos practicados contra el orden económico y financiero y contra la economía popular.

29 Artículo $333^{\circ}$.- La actividad económica y la iniciativa privada son libres, dentro de los límites del bien común. Para su ejercicio, nadie podrá exigir permisos previos ni requisitos, son autorización de la ley. 
En términos generales, sin perjuicio de la aparente discrepancia en cuanto a un grupo de Constituciones que prohíben el monopolio y las que se limitan a prohibir ciertas prácticas desarrolladas por estos, en los hechos la legislación y jurisprudencia de los países han interpretado la prohibición a los monopolios como una limitaición al Estado a entregar monopolios a particulares, antes que como la prohibición a que estos existan como consecuencia de la interacción de consumidores o proveedores.

Si una va a regular un tema complejo, debe usar una redacción simple y clara. Por ello, si entendemos que el monopolio como situación no puede ser prohibida, entonces no usemos una redacción cuya literalidad puede llevar a confusión. Es mejor redactar de manera directa que lo que nos preocupa son las conductas, estatales o privadas, que nos llevan de manera indebida a la pérdida del derecho de opción de los consumidores. Pero no limitemos a los consumidores su derecho a optar por una sola empresa si asílo desean hacer.

\section{El tratamiento de los monopolios en los tratados de Integración}

Tal como ocurriera con el Tratado de Roma en la Unión Europea, comentado líneas arriba, virtualmente todos los mecanismos de integración regional vigentes o que se vienen negociando, recogen explícita o implícitamente regulaciones sobre el tratamiento de los monopolios y las prácticas restrictivas de la libre competencia. Ello obedece, como se ha declarado en las negociaciones del ALCA, a la necesidad de evitar que la

La libre competencia económica es un derecho de todos que supone responsabilidades.

La empresa, como base del desarrollo, tiene una función social que implica obligaciones. El Estado fortalecerá las organizaciones solidarias y estimulará el desarrollo empresarial.

El Estado, por mandato de la ley, impedirá que se obstruya o se restrinja la libertad económica y evitará o controlará que personas o empresas hagan de su posición dominante en el mercado nacional.

La ley delimitará el alcance de la libertad económica cuando así lo exijan el interés social, el ambiente y el patrimonio cultural de la Nación.

30 Artículo $244^{\circ}$. - Dentro del sistema de economía social de mercado al Estado le corresponderá:

(...)

3) Promover el desarrollo de actividades y mercados competitivos. Impulsar la libre competencia y sancionar, conforme a la ley, las prácticas monopólicas y otras que la impidan y distorsionen. 
eliminación de barreras gubernamentales al comercio y a la actividad económica sean sustituidas por barreras privadas creadas por prácticas restrictivas de la competencia.

Desconocemos la existencia de algún sistema de integración regional o subregional que, al regular el tema de la libre competencia, haya establecido una prohibición de los monopolios. La línea ha seguido como estándar la prohibición de conductas antes que de situaciones. La posición de dominio no es lo sancionado, sino el abuso de tal posición o el desarrollo de prácticas restrictivas.

Es importante tener esto en cuenta porque el marco internacional es un condicionante importante. Si bien los tratados tienen jerarquía infraconstitucional, redactar una Constitución sin tener en cuenta como ésta puede afectar la posibilidad que nuestro país tiene de integrarse al mundo es virtualmente una decisión suicida que nos conduce al aislamiento. En ese sentido corresponde a la Constitución establecer esquemas flexibles en puntos críticos, como serían las regulaciones de competencia. Por ello establecer regímenes que se salgan de los estándares internacionales nos conduce a elevar los costos de la integración sin motivo alguno.

Ya en las negociaciones del ALCA este es un tema vigente. Existe ya un Grupo de Trabajo de Políticas de Competencia y un mandato dirigido a la inclusión de un capítulo sobre el tema en el Tratado. Las discusiones orientan el tema dentro del marco precisamente consistente con la no prohibición de los monopolios, sino solo de las prácticas que distorsionen la competencia. Si bien aún no se cuenta con un texto, nada hace pensar que este se alejará de la tendencia internacional. A pesar que no hay consenso sobre como será el capítulo que se incluirá en el tratado, ya existen algunos puntos importantes recogidos en las negociaciones.

En primer lugar, se habla de un conjunto básico de principios. $\mathrm{Ni}$ siquiera se ha propuesto alguno referido a la prohibición de monopolios. Por el contrario, los principios recogidos se enmarcan dentro de la línea del combate de prácticas.

En segundo lugar, se piensa establecer un esquema de cooperación entre autoridades nacionales para la investigación de prácticas (el llamado principio del "positive comity") y que también parte del supuesto de la detección y sanción de prácticas, no de situaciones.

A diferencia del ALCA, que está en negociación, en el marco subregional andino ya se cuenta con un texto vigente. Así, la Decisión No 285 del 
Acuerdo de Cartagena, que regula a los países integrantes de la Comunidad Andina, ha establecido un régimen de libre competencia que claramente sanciona las prácticas y no el monopolio en sí mismo. Tener un régimen diferente a nivel nacional solo creará una distorsión injustificada y un tratamiento diferenciado sin base según la actuación afecte o no más de un país de la subregión.

En esa orientación el artículo $1^{\circ}$ de la Decisión ${ }^{32}$ claramente se refiere a la sanción de las prácticas, y descarta cualquier regulación del monopolio por el solo hecho de ser tal. Bajo esta norma se sancionan dos categorías de prácticas. La primera son los llamados acuerdos, actuaciones paralelas o prácticas concertadas (recogidas en el artículo $4^{\circ}$ de la Decisión); y la segunda, son los casos de abuso de posición de dominio (recogidos en el artículo $5^{\circ}$ de la Decisión). Basta una breve y superficial revisión de la norma para tener claro que en ningún momento se sanciona al monopolio.

El nuevo texto de Decisión que se viene negociando y que posiblemente sustituirá a la Decisión No 285 en un plazo relativamente breve sigue en la misma línea, incluso con mayor claridad. Así mantiene la idea que lo sancionable son las prácticas y no la situación de posición de dominio y no existen elementos de juicio que indiquen que dicho criterio será objeto de revisión y menos aún de cambio. Lo que el proyecto de norma precisa es cuáles casos son considerados prácticas restrictivas con prohibición absoluta (básicamente carteles de precios) y cuáles pueden ser objeto de justificación a pesar que sean llevadas a cabo por empresas que tienen posición de dominio. Pero no existe sanción ni prohibición de monopolios.

Una modificación constitucional en el sentido de prohibir el monopolio solo entorpecería la implementación y negociación de tratados de integración al crear un elemento distorsionante a la línea que se viene siguiendo a nivel internacional.

\section{El problema de los monopolios legales}

A diferencia de lo que ocurre con los monopolios en general, que no pueden en la práctica ser prohibidos por la Constitución, los monopolios

31 Artículo 61․- El Estado facilita y vigila la libre competencia. Combate toda práctica que la limite y el abuso de posiciones dominantes o monopolios. 
legales sí pueden serlo. Ello porque, como ya se dijo, los monopolios legales son consecuencia de una conducta cuyo agente es perfectamente identificable: el Estado que los crea o fomenta. En realidad, la prohibición de los monopolios legales es la prohibición de una conducta que solo puede ser desarrollada por una persona específica: el Estado mismo.

Prohibir un monopolio legal es imponer tanto al Poder Legislativo como al Poder Ejecutivo, una limitación a la creación, sean decisiones legislativas, reglamentarias o administrativas, de barreras de acceso al mercado que no guardan relación con las preferencias de los consumidores.

Así, pueden caer dentro de esa prohibición de monopolio legal una ley que establece que solo podrá entregarse una actividad productiva a un número determinado de competidores, o crear reglas que exijan requisitos tan absurdos para desarrollar una actividad que solo un número limitado de empresas puede cumplirlas. ${ }^{33}$

32 Artículo $1^{\circ}$.- Las normas previstas en la presente Decisión tienen por objeto prevenir y corregir distorsiones en la competencia que son el resultado de prácricas restrictivas de la libre competencia.

33 Ello hace tan importante el rol del INDECOPI para proteger la competencia a través de la Comisión de Acceso al Mercado. Su rol de proteger la competencia de la creación de barreras burocráticas ilegales o irracionales debe ser bien entendido como parte del rol que el Estado desarrolla para cumplir el mandato Constitucional de prohibir los monopolios legales. Así fue reconocido por el Artículo 26 BIS del Decreto Ley No 25668 según la modificación introducida por el artículo $50^{\circ}$ del Decreto Legislativo No 807 cuyo texto señala:

Artículo 26으. BIS.-Comisión de Acceso al Mercado. La Comisión de Acceso al Mercado es competente para conocer sobre los actos y disposiciones de las entidades de la administración pública, incluso del ámbito municipal o regional, que impongan barreras burocráticas que impidan u obstaculicen ilegal o irracionalmente el acceso o permanencia de los agentes económicos en el mercado, en especial de las pequeñas empresas, y de velar por el cumplimiento de las disposiciones sobre la materia establecidas en los Decretos Legislativos No. 283, 668, y 757, el Artículo 61 del Decreto Legislativo No. 776 y la Ley No 25035 en especial los principios generales de simplificación administrativa contenidos en su Artículo $2^{\circ}$ así como las normas reglamentarias pertinentes. Ninguna otra entidad de la Administración Pública podrá arrogarse estas facultades. La Comisión, mediante resolución, podrá eliminar las barreras burocráticas a que se refiere este artículo.

(...)

Lamentablemente esas facultades han sido progresivamente siendo limitadas, hasta que la nueva Ley del Procedimiento Administrativo General ha limitado su facultad de eliminar barreras creadas por ciertas disposiciones municipales.

Con ello se ha retrocediendo de manera importante en el cumplimiento del mandato constitucional. 
Por su parte el Tratado de Roma, virtualmente la Constitución de la Unión Europea tampoco prohibe el monopolio, sino la práctica monopólica. Con una estructura similar a la Sherman Act, regula en su artículo 85 los acuerdos entre competidores, y en el 86 el tema del abuso de posición de dominio en el mercado. Este último artículo, más pertinente al tema del monopolio, tampoco lo prohibe, y solo sanciona el aprovechamiento indebido de una posición de dominio. ${ }^{34}$

El Estado, por definición, tiene el monopolio de las decisiones estatales. La mayoría de monopolios o concentraciones dañinas para los consumidores provienen precisamente de la "transferencia» de dicho poder a empresas que se benefician de ello. Así, el Estado en uso de sus facultades normativas y administrativas suele crear barreras de acceso para permitir que unos pocos se queden en el mercado. Esto le da a las empresas beneficiarias de tales barreras la posibilidad de cargar precios más altos y reducir las opciones de los consumidores. Permitir que esos monopolios se creen, es abrir el camino para que las presiones impropias, el lobby o incluso la corrupción, permitan a las empresas obtener privilegios que eliminan la posibilidad de competencia efectiva, en perjuicio de los consumidores.

Por ello, son de una precisión admirable las palabras del jurista peruano Francisco García Calderón quien en 1879 (hace más de un siglo y varios años ante de la promulgación de la Sherman Act en los Estados Unidos) al hablar de la causa principal de los monopolios, señaló:

«[...] toda medida que limita la libertad de industria, trae como consecuencia el monopolio: la formación de gremios y matrículas, la imposición de contribuciones industriales, las vejaciones hechas a los vendedores en las ferias y mercados, y otras disposiciones emanadas del sistema restrictivo, traen inmediatamente el monopolio; y si entonces se reduce el precio de las mercancías por una ley, se comete una nueva injusticia, y se hace un nuevo ataque a la libertad. La libre concurrencia, que permite que los precios suban y bajen según su ley

34 Artículo $86^{\circ}$.-Será incompatible con el mercado común y quedará prohibida, en la medida en que pueda afectar al comercio entre los Estados miembros, la explotación abusiva, por parte de una o más empresas, de una posición dominante en el mercado común o en una parte sustancial del mismo.

(...) 
natural, es el único medio de impedir los monopolios: las disposiciones directas o indirectas del gobierno y de las actividades son ineficaces para conseguir ese objeto: así lo acredita la experiencia de todos los días. $)^{35}$

Y lo más serio es que el monopolio legal no permite que nos consolemos con la esperanza que futuros entrantes al mercado, es decir, nuevos competidores; van a corregir el problema. Los precios mayores que el monopolio carga no cumplirán el rol de crear incentivos para nuevos entrantes porque por definición esa entrada está prohibida o limitada precisamente por la acción estatal. Hasta la más efectiva práctica privada para impedir la entrada de competidores puede ser superada. Lo mismo no ocurre con las barreras estatales por que superarlas implica, por definición, cometer un acto ilegal. El resultado es la perpetuación de la ineficiencia o la generación de informalidad, esa es la respuesta que los peruanos hemos dado sistemáticamente a las reglas y regulaciones absurdas que limitan la competencia.

En ese sentido, debe mantenerse en principio y con algunas precisiones, la redacción actual del artículo $61^{\circ}$ de la Constitución en tanto que limita la prohibición solo a los monopolios legales.

\section{Aspectos económicos de la prohibición de monopolios}

\section{a. La protección de los consumidores}

Sin perjuicio de los antecedentes legales que se han mencionado, no debe de perderse de vista la problemática económica que rodearía la prohibición a rajatabla de los monopolios para los consumidores.

El tamaño de una empresa es muchas veces un sinónimo de eficiencia. La eficiencia implica, entre otros elementos, minimizar los costos. Ello, porque conforme una empresa crece sus costos fijos se mantienen constantes y se dividen entre un número mayor de unidades de producto. Así, el costo marginal, es decir, el costo de producir una unidad adicional de un producto, va decreciendo.

35 Francisco García Calderón, Diccionario de la Legislación Peruana, Segunda Edición, París/Lima, p. 1375. 
Esto hace no solo que los precios bajen, sino que se utilicen una cantidad menor de recursos para producir lo mismo. Eso significa mayor bienestar social con un mejor uso de los recursos. Ello claramente favorece a los consumidores:
"[...] el «antitrusti no debe interferir con ningún tamaño de empresa creado por crecimiento interno y esto es verdad sin importar cuando el resultado es un monopolio o un oligopolio. La mayor probabili- dad es que cualquier interferencia como esa desencadenará una pér- dida neta en el bienestar de los consumidores." ${ }^{36}$

En ese sentido las normas de competencia se han enfocado a proteger a los consumidores. Ello no solo se deriva de nuestra legislación, sino de la propia jurisprudencia del INDECOPI al resolver casos vinculados a prácticas anticompetitivas.

Algunos ejemplos extremos ayudan a comprender este punto. En industrias de altos costos fijos, como sería por ejemplo el agua potable, los consumidores se perjudicarían de forzar la existencia de un mayor número de competidores. Para tener competencia se necesitaría dos redes completas de agua potable. El costo de construir dos redes completas para una ciudad simplemente duplicaría un gasto que tendrá que dividirse entre el mismo número de consumidores. El resultado es que la tarifa del agua sería más cara a si tuviéramos solo una empresa produciendo.

Un segundo elemento a tomarse en cuenta es el impacto de potenciales entrantes en el bienestar de los consumidores. Así, si bien podría parecer en ocasiones que la empresa no soporta competencia, en la realidad sí soporta competencia potencial. Así, la existencia de un «monoproductor» nacional en el mercado y la inexistencia de importaciones significativas, no quiere decir que la potencial entrada de productos extranjeros o la potencial aparición de nuevos competidores locales controlen al aparente monopolista. Y al hacerlo el interés de los consumidores estará protegido.

En ese sentido, la mayoría de las definiciones en las leyes de competencia establecen que existirá posición de dominio cuando una empresa pue-

36 Robert Bork, The Antitrust Paradox, Maxwell Macmillan, New York, 1993, p. 178. Traducción libre del siguiente texto: "[...] antitrust should not interfere with any firm size created by internal growth and this is true whether the result is monopoly or oligopoly. The high probability is that any such interference will lead to a net loss in consumer welfare". 
de actuar con independencia de sus competidores o clientes por factores tales como su participación de mercado, las condiciones de oferta y demanda, el acceso a insumos o a fuentes de financiamiento, entre otras. Eso significa que la empresa en cuestión no sería lo que se llama un «tomador de precios" del mercado. Cuando existe competencia las empresas se comportan como tomadores de precios, esto es, que no están en posibilidad de fijar sus precios de manera independiente porque la existencia de competidores limita su facultad. Así si fijan precios muy altos, por encima de los que se pueden tomar del mercado, perderán ventas y eventualmente saldrán del mercado.

A veces se puede apreciar un solo proveedor, pero este no puede actuar con independencia, es decir, este es un tomador de precios. Por ejemplo, la existencia de una sola marca de cerveza no significa que el fabricante actúe como un monopolio. De pronto actúa solo en el mercado porque el flete que tendría que pagar sus potenciales competidores para transportar cerveza a dicho mercado los sacarían de competencia. Pero el monoproductor no puede subir el precio porque apenas lo hiciera daría margen a que entrara su competencia. Así, el aumento de precios daría espacio para que el potencial competidor asuma el costo del flete. En consecuencia, ${ }_{2}$ no puede actuar con independencia de sus competidores y clientes. ${ }^{37}$

Algo similar ocurre con la sustitución de producto del presunto monopolista por otros productos distintos pero que son sustitutos. En realidad, es relevante para saber si alguien es o no un tomador de precios, hacia donde girarían los consumidores si el productor en cuestión decide subir su precio. En ese caso si los consumidores encuentran que su necesidad y preferencia puede ser satisfecha con otro producto, entonces el productor se vuelve un tomador de precios pues no puede actuar con independencia de los productores de estos otros productos.

Regresemos al ejemplo de la cerveza. Si existiera una sola marca de cerveza en el mercado, ello no significa que tenga un monopolio. Si el

37 En el análisis que se hace en las legislaciones de competencia a esto se le llama definición de mercado relevante geográfico, y que no es otra cosa que la definición de dónde enfrentaría una empresa competencia. Dependiendo de la capacidad que tienen los competidores de entrar a ofrecer sus productos o de los consumidores de buscar otras alternativas en otro lugar, se amplía o reduce el mercado geográfico. Este puede ser un barrio, un distrito, una localidad mayor, una provincia, una región, una zona mayor del país, un grupo de países o el mundo entero. Todo depende de las condiciones existentes. 
fabricante de esta cerveza subiera su precio y la gente comenzara a beber ron, aguardiente o vodka, entonces esas bebidas deben incluirse en el mercado relevante y en consecuencia el supuesto poder de mercado se diluye ante la existencia de otros competidores. ${ }^{38}$

Lo que muestran estos elementos es lo difícil que puede ser determinar cuándo un monopolio real o aparente, afecta negativamente a los consumidores. Y dada esa dificultad se corre un riesgo notable que la prohibición a rajatabla de los monopolios sea peor para los consumidores.

\section{b. La competitividad de la industria nacional en el mercado.}

Un elemento adicional que ya se ha mencionado pero que conviene profundizar es el pertinente a la competitividad de la industria nacional como consecuencia de la adopción de un modelo de prohibición de los monopolios.

Como ya vimos, la competitividad depende de la eficiencia de una empresa y la eficiencia depende de la capacidad de la empresa de reducir sus costos de producción. Una forma de hacerlo es creciendo para reducir así el costo marginal, evidentemente siempre que la demanda existente lo permita. Con ello, las empresas alcanzarán las economías de escala, es decir, eficiencias derivadas del tamaño de la estructura productiva. Así lo explican Areeda y Kaplow:

"[...] eficiencia-mencionada aquí en el sentido de producir y distribuir al mínimo costo-suele requerir negocios más grandes. La especialización del trabajo y las complicadas técnicas de producción pueden ser explotadas de mejor manera cuando la producción se hace a escala mayor. Grandes máquinas con gran capacidad son más rentables si sus costos pueden distribuirse entre una base mayor de actividad e industrias de procesamiento como la de refinería petrolera dis-

38 Esto se conoce en la aplicación de la legislación de libre competencia como la definición de mercado relevante de producto. Así, dos productos muy similares podrían no estar en el mismo mercado. Los automóviles Mercedes Benz no están en el mismo mercado que los automóviles Tico de Daewoo, pero quizás sí estén en el mercado de los $\mathrm{BMB}$ o de los VOLVO. Pero quizás dos cosas tan distintas como "alarmas a distancian y "cerraduras de seguridad" sí estén en el mismo mercado, si al subir el precio d e uno, los consumidores de estos productos se pasan al otro. 
fruta de economías «naturales» de escala [...]. Si los grandes tamaños permiten la reducción de costos y si algunas empresas alcanzan esas economías, sus rivales deberán buscar alcanzar las mismas economías para sobrevivir. En consecuencia grandes empresas incrementan al espectro de mayor concentración. Pero incluso si las economías de escala nos llevan a precios monopolísticos, los ahorros de costos pueden ser tan sustanciales que un precio monopolístico que maximiza utilidades y producción será más favorable, o no menos favorable que si el mercado tuviera un gran número de empresas menos eficientes.n $)^{39}$

En un sentido similar se pronuncia Richard Posner:

«Los costos resultantes del precio monopolístico serán en ocasiones menores que los ahorros de costos generados por tal precio. Imaginemos la creación de un monopolio êin un mercado tan pequeño en relación a la escala eficiente de producción que una sola empresa tendría costos mucho menores que los que se enfrentaría con más de una empresa -muchos más bajos, incluso, cuando el actual precio monopolístico que maximiza utilidades esta incluso debajo que el precio competitivo. Simplemente, el bienestar económico de la sociedad será mayor si el monopolio es permitido a si es prohibido y en consecuencia, en un análisis económico, valorizamos la competencia por que promueve eficiencia, el monopolio debe ser permitido, incluso promovido. ${ }^{40}$

39 Phillip Areeda y Louise Kaplow, Antitrust Analysis, Little, Brown and Company, Boston, p. 32. Traducción libre del siguiente texto: «efficiency- bere in the sense of production and distribution at minimum cost-is often said to require bigness in business. Specialization of labor and complicated production techniques can be exploited more fully when production runs are long. Large high-capacity machines are more profitable if their costs can be spread over a wide base of activity. And process industries like petroleum refining enjoy 'natural' economies of scale [...] If larger size permits cost reductions and if some firms achieve such economies, their rivals must seek the same economies in order to survive. Thus, large-firm economies raise the specter of increasing concentration. But even if scale economies lead to monopoly pricing, the cost savings may be so substantial that a monopolist's profit-maximizing price and output would be more favorable, or no less favorable than if the market had a large number of less efficient firms"

40 Richard Posner, Antitrust Law, The University of Chicago Press, Chicago, 1976, p. 22. Traducción libre del siguiente texto: "The costs resulting from monopoly pricing will 
En una economía pequeña como la peruana alcanzar economías de escala implica participaciones mayores en el mercado local. Solo así es posible que las empresas puedan competir con empresas transnacionales $o$ que provienen de mercados que, por su tamaño, les permiten alcanzar economías de escala.

Prohibir el monopolio equivale a limitar la capacidad de nuestras empresas de competir en el mercado nacional con entrantes de fuera y a su vez impedirle a la empresa nacional salir a competir afuera en igualdad de condiciones. Ya nuestro país tiene problemas, por el tamaño de nuestra demanda, para sustentar una estructura empresarial competitiva aprovechando economías de escala. La prohibición de los monopolios solo contribuye a agravar una situación ya de por si difícil.

Por ello, la Constitución debería poner mucho más énfasis en limitar la capacidad del Estado para crear barreras que fomenten la monopolización, tanto en el comercio internacional como en las regulaciones internas. Finalmente, son esas barreras las que generarán verdaderas distorsiones. Pero debe dejarse que las empresas puedan desarrollar sus propias capacidades competitivas. No olvidemos que hoy debemos enfrentar la competencia global y ello implica que nuestra Constitución permita el desarrollo de estructuras capaces de competir con eficiencia.

\section{c. Los costos de «enforcement» de la prohibición.}

Finalmente, sin perjuicio de la inconveniencia de la prohibición, existe una imposibilidad real de ejecutarla.

Como ya se vio, ejecutar una prohibición como la que es objeto de discusión implica definir para cada industria comprometida tanto el mercado relevante geográfico como el de producto. Pero además hay que hacerlo continuamente por que las condiciones de mercado cambian dinámicamente. El costo de un sistema de monitoreo continuo de todas las industrias es prohibitivo.

sometimes be lower than the cost savings generated by such pricing. Imagine the creation of a monopoly in a market so small in relation to the efficient scale of production that a single firm will have much lower costs than more than one firm - so much lower, indeed, that the profit-maximizing monopoly price is actually below the competitive price. Plainly, society's economic welfare would be greater if the monopoly were permitted than if it were forbidden, and since, in an economic analysis, we value competition because it promotes efficiency it should be tolerated, indeed encourageds 
Solo a título de ejemplo, se puede referir a los inmensos costos que generan los sistemas de control de fusiones en donde se han implementado, costos que difícilmente justifican los supuestos beneficios que generan. Estos costos no son solo los que se generan para la actividad estatal que debe desarrollarse, sino los que un sistema como este genera para las empresas que tienen que satisfacer sus exigencias y asumir la incertidumbre de las decisiones discrecionales de la administración pública.

En esa línea prohibir los monopolios no es solo absurdo, sino económicamente irrealizable. Sin duda implicará embarcarse en una actividad no solo imposible de cumplir, sino que tendrá costos que claramente superarán a los inciertos beneficios que supuestamente generaría.

\section{1. ¿Y quién debe sancionar las prácticas que afectan la competencia?}

Finalmente, hay un tema que la Constitución de 1993 no se animó a abordar, y es la jerarquía constitucional del ente encargado de aplicar las normas de protección a la competencia. Si bien en el debate estuvo en discusión la probabilidad de darle reconocimiento constitucional a la agencia de competencia, finalmente ello se descartó.

La oportunidad de una reforma constitucional puede contribuir a dar tal reconocimiento, el cual es recomendable por dos razones principales:

a. La especialización de la temática hace recomendable la existencia de un órgano cuyas decisiones solo sean revisables en vía judicial o, en todo caso, tengan una revisión limitada a aspectos formales. Por ello, el reconocimiento constitucional en ese sentido hubiera sido recomendable. Lo ideal sería la creación de Cortes especializadas a cargo de estos temas.

b. La necesidad que para velar por la competencia la agencia respectiva pueda revisar actos de otras entidades del Estado hace recomendable u reconocimiento constitucional que haga de dicha facultad una incuestionable. Esto está principalmente vinculado al tema del acceso al mercado y las barreras burocráticas. 


\section{Conclusión}

La Constitución es la máxima norma de nuestro sistema jurídico. Pero ni con toda su jerarquía puede derogar la realidad. La existencia de monopolios tiene un sustrato real: a veces son la mejor forma de hacer las cosas.

En esa línea una Constitución poco realista se conduce a sí misma a la su inaplicación, y con ello reduce la posibilidad de que su jerarquía jurídica se convierta en una auténtica jerarquía valorativa para los ciudadanos.

En esa línea el texto constitucional de 1993 es, en este aspecto, muy superior al texto de 1979. Retroceder sería un error. En todo caso, se puede aprovechar la situación para seguir avanzando en el sentido correcto.

En esa línea consideramos que al tratar el tema de la libre competencia el texto constitucional debe ajustarse a las siguientes líneas matrices:

a. Reafirmar el rol de Estado como ente encargado de promover la libre competencia.

b. Mantener la línea de no prohibir el monopolio, sino la práctica que atente contra la libre competencia.

c. Hacer precisiones técnicas al lenguaje de la Constitución orientadas a una mejor identificación de las prácticas consideradas ilegales, de cuerdo a la legislación y doctrina comparadas.

d. Reforzar y precisar su redacción a fin de evitar que se creen monopolios legales por la vía de la acción del Estado.

e. Reconocer jerarquía constitucional a la agencia o autoridad encargada de velar por la libre competencia.

Dentro de esos lineamientos sugerimos que, de efectuarse una reforma del primer párrafo del artículo $61^{\circ}$ de la Constitución, este debería quedar redactado de la siguiente manera:

«El Estado facilita y vigila la libre competencia. Combate toda práctica restrictiva de la competencia y el abuso de posiciones dominantes o monopólicas. Ninguna Ley o acción del Estado puede establecer monopolios o restricciones a la competencia.

La defensa de la competencia está a cargo de un organismo especializado con facultades suficientes reconocidas en la Ley" 
El poder constituyente tiene el «monopolio" para definir las líneas centrales de nuestro destino. Como todo monopolio, no debe dar lugar a abusos, sino a un ejercicio responsable. Y la responsabilidad principal, en este caso, es con los consumidores. Los consumidores suelen ser las víctimas ocultas de las iniciativas que, curiosamente, se impulsan para beneficiarlos. Ello, por que a veces para protegerlos les quitamos capacidad de decisión. Finalmente es la competencia su mejor aliado. Y es la competencia el mayor enemigo de los monopolios que no sustentan su éxito en las preferencias de los consumidores. 